HARRIET EVANS

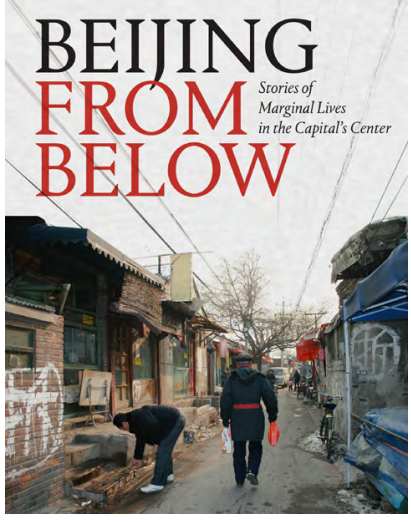

Beijing from Below: Stories of Marginal Lives in the Capital's Center (Duke University Press, 2020).

\section{Beijing from Below A Conversation with Harriet Evans}

Andrea Enrico PIA

Harriet EVANS

$\mathrm{n}$ her new book, Beijing from Below: Stories of Marginal Lives in the Capital's Center (Duke University Press, 2020), Harriet Evans captures the last gasps of subaltern life in Dashalar, one of Beijing's poorest neighbourhoods. Between the early 1950s and the accelerated demolition and construction of Beijing's 'old city' in preparation for the 2008 Olympic Games, the residents of Dashalar lived in dilapidated conditions without sanitation. Few had stable employment. Today, most of Dashalar's original inhabitants have been relocated, displaced by gentrification. Drawing on oral histories that reveal the memories and experiences of several neighbourhood families, Evans reflects on the relationships between individuals, families, and the state; poverty and precarity; gender politics and ethical living; and resistance to and accommodation of the authority of the Party-State.

Andrea E. Pia: Along with a number of other scholars, including Luigi Tomba, Mun Young Cho, Sun Wanning, and Joel Andreas, your book serves to refocus attention on class formation and class identity in the study of China, and especially of its urban margins. Your approach can also come across as an attempt at re-narrating what we could call the internal frontiers of the state-places where undesirable subjects, often portrayed as standing in the way of development, are dealt with through a combination of punitive law-and-order policing and laissez-faire state neglect. Why is it useful to think about contemporary Chinese society from a subaltern position-from 'below', as your title indicates? What does this choice of register, including the question of class, add to our current understanding of contemporary China?

Harriet Evans: I address class rather more indirectly than the scholars you mention here, since I do not embark on any head-on interrogation of the structures producing my interlocutors' marginalisation. What is also different is my focus on long-term residents with formal household registration to Dashalar, and not mainly migrants, as in Sun Wanning's analysis-although one of the chapters that was the most emotionally demanding to write concerned a migrant couple and their two children who moved to Beijing from Shaanxi in 1997. So, the marginal status of my urban subaltern interlocutors was reproduced and reiterated time and again over the long decades I cover in the book, and most notably during the Mao era. This then addresses a subaltern category not accounted for over the same period in the available literature. 


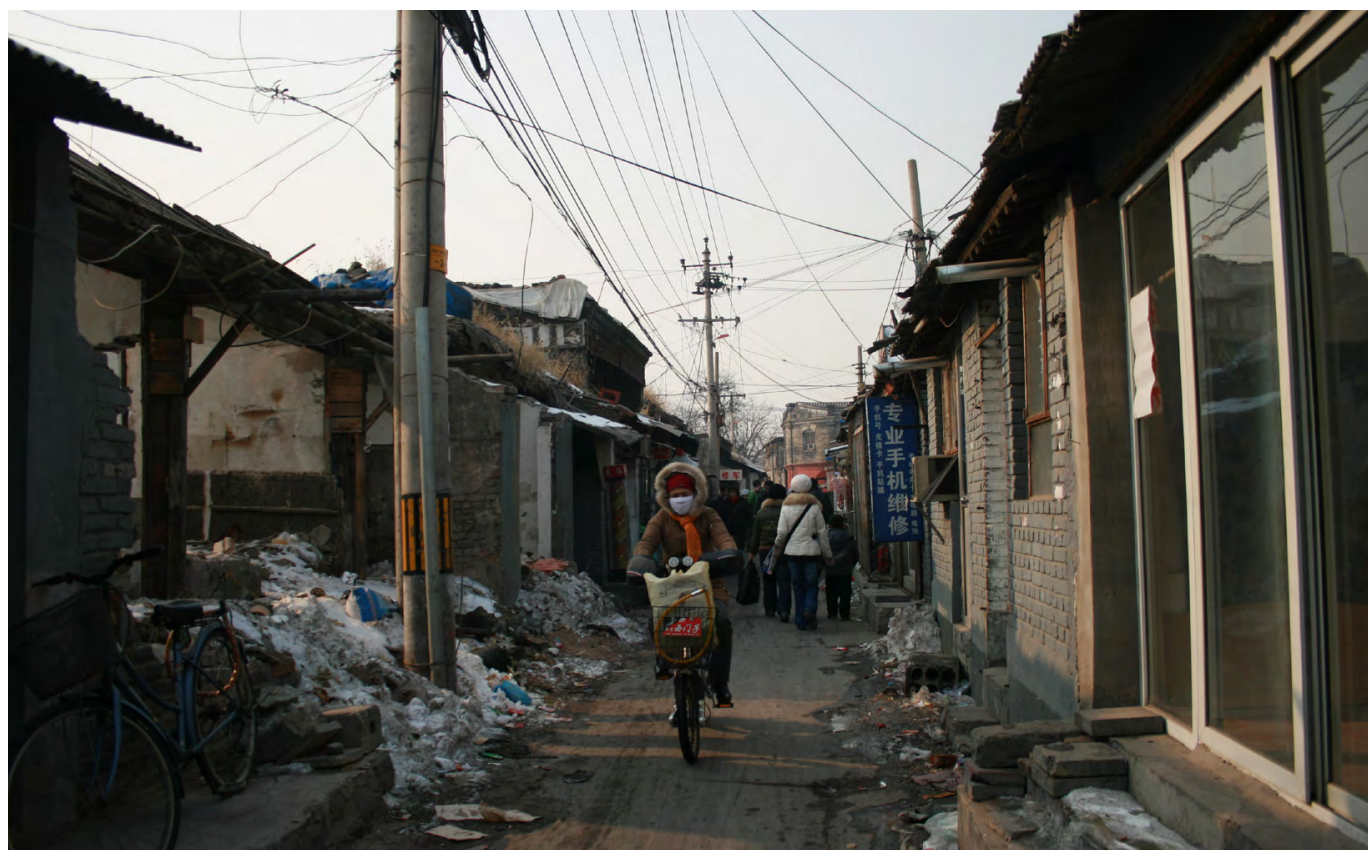

Dashalar hutong in winter. PC: Harriet Evans.
The issue of subalternity in the Mao era is complex and awaits more proper theoretical analysis than I give it in the book. There is, moreover, one character in my book who was enabled by his upbringing, chance encounters, and entrepreneurial savvy to acquire a material standard of living that would characterise him in class terms rather differently from the others whose stories I narrate. The most obvious 'fit' between an individual's experience-always mediated by memory-and subalternity is Old Mrs Gao, whose childhood of destitution and child marriage during the Republican era denied her the possibility of even imagining an education. Come the People's Republic, her illiteracy and lack of employable skills confirmed her status on the margins of the new, proud working class.

However, thinking about the differences between the people I got to know so well over the years I visited them, the conditions of 'subalternity' that I associate with Meiling, the woman who felt abandoned by her parents and eventually ended up in detention for prostitution in the Anti-Spiritual Pollution campaign of the early 1980s, and Zhao Yong, whose subaltern status was the effect of 'inheriting' his grandparents' political categorisation as 'small landlords' and his family's reputation for madness, beg all sorts of questions about the effects of political and administrative controls in producing a 'declassed' stratum outside the formal class structures of the Party-State. We know that the creation of an ostracised class category outside the classifications recognised within the political terms of the 'people' (人民) and then the 'dictatorship of the proletariat' was a deliberate attempt by the Party-State to isolate and 
Inside a half-demolished dazayuan. PC: Harriet Evans.

'punish' those identifying with and inheriting a class categorisation deemed to conflict with the goals of socialist transformation. But in the available literature on this, privileged attention has been given to the educated 'professional' stratum of urban-centred individuals. Little attention has been given to those whose 'bad' status was due to class categorisation of individuals for small-scale entrepreneurial activities, such as Zhao Yong's grandparents.

For individuals such as Zhao Yong, who had clear recollections of his father being beaten by Red Guards, the Cultural Revolution was one exceptional moment in a long history of hardship and scarcity, but he made no claims to the privileged victimhood that emerges in the well-known eyewitness accounts of the late Mao era. He had no personal stakes in producing an account of suffering during the Cultural Revolution. For him, the Cultural Revolution was not a 'state of exception', to use Agamben's terms, nor a historical blip on what would otherwise have been a seamless transition from the capitalism of the Republican era to the post-Mao market reforms. Rather, it was but one moment in a longer painful history of scarcity, neglect, and discrimination running throughout his entire life. The point I am making is that the accounts responsible for constituting our knowledge of the Cultural Revolution are largely framed by the class backgrounds of their authors.

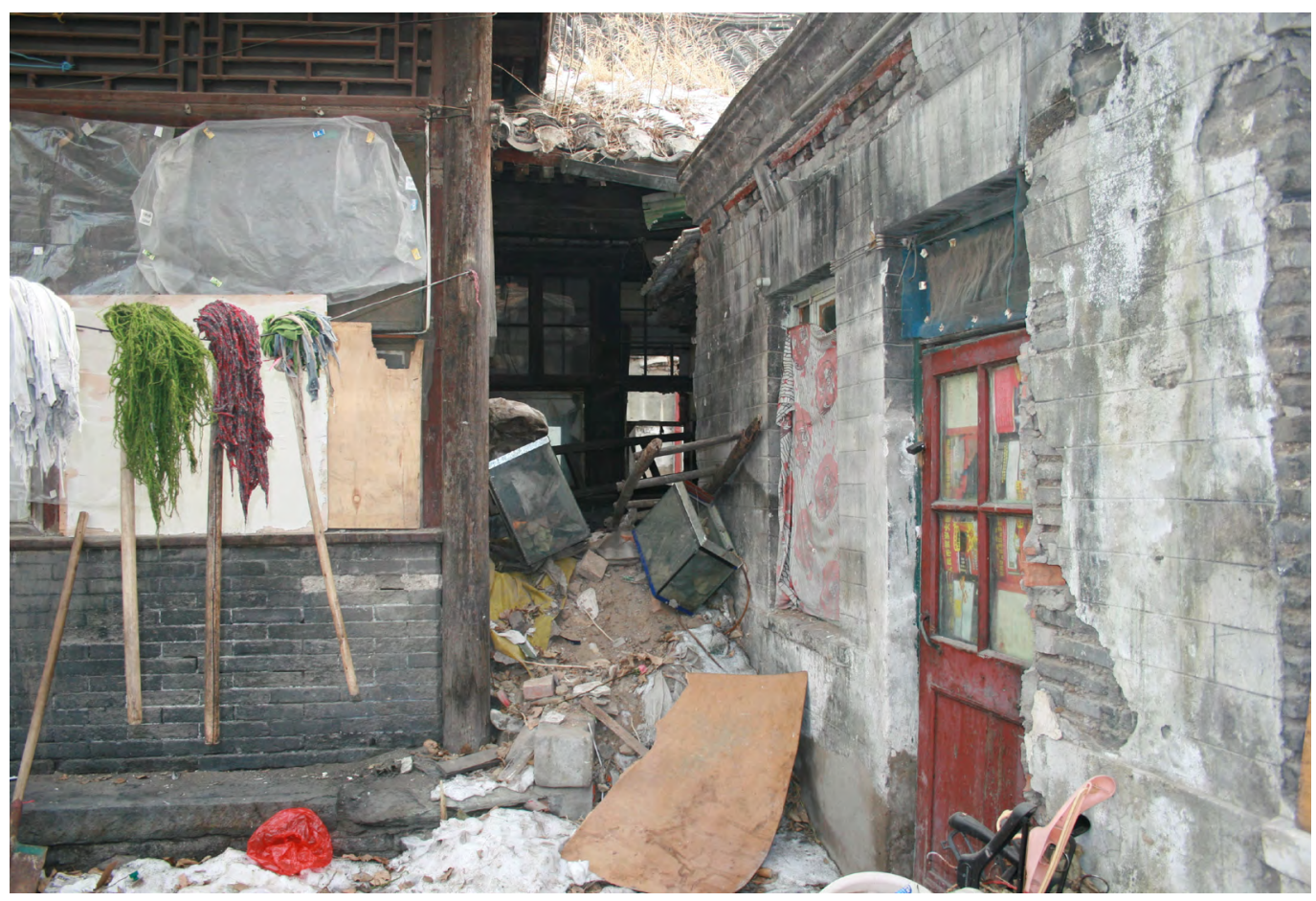


CONVERSATIONS

Another point I want to make concerns your comment about how I re-narrate what could be thought of as 'the internal frontiers of the state'. Yes, the people whose stories I tell were seen as undesirable subjects. The archival record says as much, as do my subjects' narratives. However, the way I approached this in the book is by showing how the Dashalar residents I knew were so removed from the direct discursive and institutional arm of the state that the state's temporality played no significant role in their framing of their own lives. But the notion of the 'internal frontiers of the state' opens up the space for thinking also about the liminality and porosity of the frontier. For example, in her work on rethinking subaltern urbanism, Ananya Roy (2011: 226) defines 'the slum' as a space of 'vibrant and entrepreneurial urbanism'. While I would argue that, from a phenomenological perspective, this space may be experienced and mediated by both these alternatives, the concept certainly enables us to think of the 'frontier of the state' as a space where contending forces oscillate for influence, a space that conceptually confers recognition on urban subalterns, while also permitting the coercive weight of the Party-State. The main ethnographic instances of this in my book would be the detention of Meiling for prostitution, the traffic policeman's attempt to fine Zhao Yong for some minor infraction, in response to which Zhao was detained for 24 hours, or the chengguans' brutal treatment of the migrant Li Fuying for riding his pedicab without a licence.

AEP: Your book is notable for its methodological choices and narrative structure. Here, you combine ethnographic fieldwork, archival research, and techniques of oral history to cover almost 60 years in the social history of Dashalar, which you visited on and off over many years. I particularly admired your rendition of the rhythms and tempos of your interlocutors' narratives-the pauses and idiosyncrasies typical of direct speech that the oral historian Alessandro Portelli (2017: 31) famously described as proof of the 'narrator's participation in their story as well as the story's participation in the narrator's life'. When reading about contemporary China, we rarely get such a vivid account of people's own understanding of their private lives, and this reinforces your argument that subaltern subjects should be represented in their own voice. But this approach may also leave the impression that, as another oral historian, Carlo Ginzburg (2019: xxii), once said, 'one cannot escape from the culture of one's class and the culture of one's time'. That is, if not analysed through explicit social justice categories, these voices could seemingly fail to provide counsel to younger generations of Chinese urbanities, who may be experiencing a more pulverised class system and more fluid gender relations. If the subaltern can indeed speak, how can we make sure that the people who should, will in fact listen?

HE: I should here point out that this book is very different from the 'traditional' conventions of oral history. I anonymised people's names, I did not take many recordings, nor did I conduct life-story interviews. That said, while we may never be able to replicate the experience of the subaltern in our ethnographic narratives, we absolutely can find ways to bring gestures of their experiences to life on 
the written page, or even in photographic form. I certainly go along with Portelli's emphasis on the stops and starts and idiosyncratic jumble of direct speech. But-as an aside-it is important to point out, given that so much oral history is inspired by an effort to give voice to those marginalised by history, that it would be a mistake to see such a jumble as indicative of class alone. Portelli's insistence on respecting the forgettings as much as the remembrances of memory is also extremely apposite to my methodology. Hence my reference to Studs Terkel's comment to the effect that it is the content of memory that is important to the subject, not its relationship to recorded fact. Where I may depart a bit from Portelli, however, is with reference to a kind of hierarchy he seems to me to imply when he comments on the archive and secondary literature as providing 'fact checks' that give clues to the imagination.

Insisting on the narrator's participation in the creation of the story also has to be interrogated. While Portelli's argument points to an ideal in the ethnographic relationship, it overlooks the imbalance in that relationship-how researcher and interlocutor may talk about the same thing but with very different understandings about its meanings. My methodology and the way I combine the different sources I use (including official archives) emerged organically out of the dynamic of my research. I did not plan them in the way they finally panned out. So, coming back to Portelli, I turned to the archive and secondary Chinese sources after getting to know the families who appear in my book, largely because I wanted to find out what, if anything, they revealed about how different centres of interest and power narrated or interpreted and/or attempted to control them as subjects of a shared history. I ended up thinking about how these different sources spoke to, across, and sometimes with each other. Not to 'fact check' but to explore where and how the experiences of my Dashalar acquaintances both subverted and at times corresponded with the interests of the state.

One aspect of my sources that I have only recently begun to think about, in large part thanks to a dialogue with Erik Mueggler, concerns the meaning of the object that I describe and visualise in the photographs that appear in the book. This adds another dimension to the exchange between the researcher and interlocutors in spaces filled with objects. So, for example, the objects that I describe in Old Mrs Gao's main room can be thought of as describing many of the main features of her life, in a way that is similar to the painting technique that builds up an image from the background and context rather than from a focus on the main figure itself. Or it can be thought of as a kind of ekphrastic depiction of Old Mrs Gao's life through a narrative description of the material and therefore visual objects she lived her days surrounded by.

Finally, conversations with historian friends and colleagues and a discussion about a couple of chapters with graduate students convinced me to take up Susan Mann's remediation of Sima Qian's 
Records of the Historian in her wonderful The Talented Women of the Zhang Family (2007) as a way of 'bringing to life' my interlocutors. This resulted in a decision on my part to narrate the main chapters in the voices of my interlocutors, as much as I could, and insert 'interludes' after each chapter to try to draw together what in my view seemed to be the main interpretative threads and themes.

So, we come to Carlo Ginzburg's quote. Ginzburg was talking about periods across space when place and experience were bounded by clearly demarcated cultural boundaries, most notably of the late Roman Empire, and when time and class were in a sense mutually constituted. In our own time, however, even within the 'closed' boundaries of Dashalar, the 'culture of one's time' includes observation of global worlds of wealth and opportunity and the possibilities of fantasising about what they might mean. And class is not a fixed category either in sociological or in subjective terms. A sociological analysis of my interlocutors in Dashalar would group them all together as members of the 'underclass' (社会底层), but an analysis that starts with memory and experience reveals sometimes significant differences in how such a category is lived. But one of the themes running through the book, as a whole, does concern the idea of 'social justice', if not as a clear-cut structural category, then certainly as a category that has affective and therefore implicitly political purchase for those wanting to claim it. I am making an argument that draws a distinction between internalised and lived ideas about class discrimination and injustice and external analyses of the structural factors producing such conditions, and that from the former position reveals the difficulties of counselling others about 'class discrimination'.

AEP: Many of your interlocutors are Beijing women of different social cohorts, who are stuck navigating the ever-shifting terrains of family obligations and gender imbalances, all while also struggling to retain some semblance of autonomy. Reading their stories, I was reminded of the work of another important Italian oral historian, the antifascist Nuto Revelli. For one of his projects, Revelli (2018) talked with Piedmontese peasant women who, interestingly, shared a migrant background similar to that of Li Fuying in your book. Importantly, Revelli notes how ambivalently these women felt about expressing their desires for greater autonomy, which could only be realised by clinging on to, and even investing emotionally in, a patriarchal authority. As with elsewhere, being a woman in China implies being subjected to multiple forms of subordination. In what ways do the stories you recount in the book add complexity and texture to debates within contemporary Chinese feminism?

HE: The notion of emotional investment in patriarchal authority is certainly a theme that is close to my heart. But to begin with, I would point out that such emotional investment is simultaneously and indivisibly ethical and instrumental. It is, moreover, by no means simply the product of or response to conditions of scarcity and precarity, as the modernisation argument favoured by so many 
mainstream Chinese sociologists would put it. I argue elsewhere that investment in a reconfigured form of patriarchy-what I call 'patchy patriarchy'-also characterises the gendered positionality of many wealthy, highly educated women, as Xie Kailing (2019) has argued. If we think of 'patchy patriarchy' as the inconsistent and contradictory ways in which women continue to uphold recognition of men's authority, while also claiming their own autonomy, then of course this is bound to be differently mediated and expressed across social, temporal, and cultural boundaries. I argue that, despite the transformative effects on women's lives of the radical policies of the early Mao era-most notably, in opening up opportunities for employment and education that positioned women as public subjects-neither the Women's Federation nor other institutions of state addressed the domestic and familial sphere. On the contrary, it was assumed that, until the state was financially able to take on the tasks of providing childcare and other domestic and welfare services, these would naturally fall to women. Moreover, women's failure to undertake such tasks would be seen as a sign of irresponsibility to the socialist cause. This position was backed up by a socio-biologistic view of gender difference according to which women were naturally bound by their physiological makeup to mother and take on other caring duties.

Then came the Fourth World Conference on Women in Beijing in 1995. This was a defining moment for many Chinese women-most notably, educated professional women, who for the first time in their lives were able to engage directly with women from all over the world, particularly the Global South. Their discussions introduced them to how women's organisations elsewhere had been tackling intractable issues of poverty, health, education, and gender discrimination in social and political conditions dominated by patriarchal authority. They also came across new understandings of gender removed from the biological definition of gender difference that they had grown up with. There was a palpable excitement as women began to debate the emancipatory possibilities of a notion of gender as a social construct, and therefore open to change. Despite the Women's Federation's ambivalence about this growing 'feminist' voice, it nevertheless signalled the dynamic creativity of engagement with international feminism.

Into the new millennium, China's status as an increasingly powerful participant in the system of global capitalism led to greater social differentiation and changing employment structures, giving many women access to unprecedented prospects of self-realisation and recognition, but also producing increased practices of gender discrimination alongside widening gender disparities, such that, by 2017, China ranked 100th out of 144 countries in the World Economic Forum's Global Gender Gap Index. Following Xi Jinping's Confucian revival, policy and dominant discourse turned 


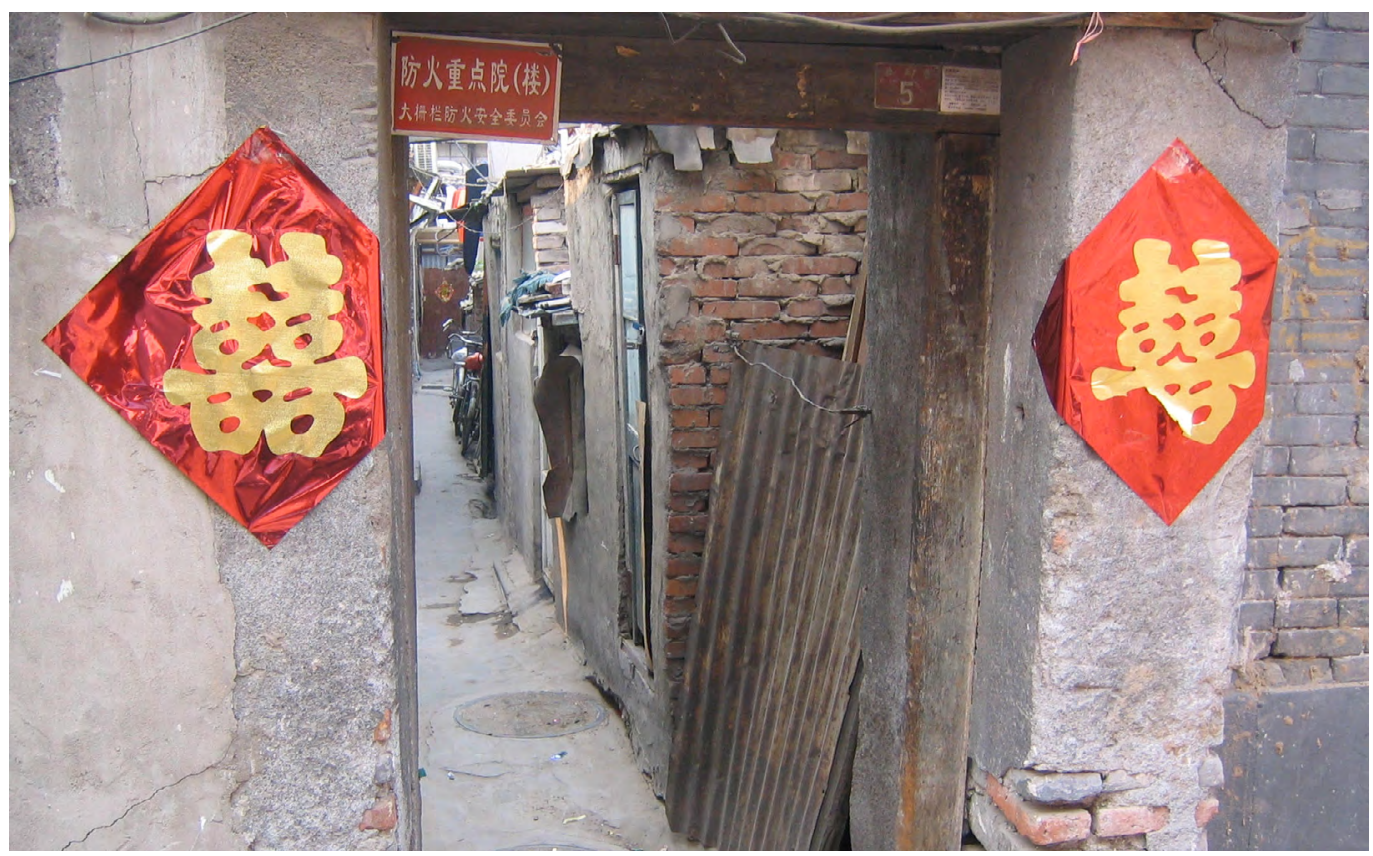

Entrance to Old Mrs Gao's dazayuan at Chinese New Year 2008. PC: Harriet Evans. to an explicit celebration of women's domestic virtues, banishing 'gender equality' to an increasingly marginal place in the language of the Party-State, including the Women's Federation.

These developments, combined with activism through social media, have produced a new generation of millennial feminists from diverse backgrounds, including LGBTQ+ activism. In contrast to their older sisters, they explicitly target marriage and family responsibilities in exploring feminist ideas that mark a radical departure from previous principles of women's emancipation and gender equality. As Fincher argues in Betraying Big Brother (2018), while this activism is seen to threaten the status quo of China's male-dominated political system, it has not curbed the explosion of online platforms for exchanges about women's empowerment in a market environment that grants them considerable leverage to manage their marital and domestic relationships.

So, the Chinese Communist Party and the Party-State have made spectacular achievements in transforming the conditions of women's lives over the past century, but 'patchy patriarchy' continues to characterise the gendered expectations and assumptions about marital and family relationships. Across class, generational, and sectoral differences, patriarchal structures in China have long since moved away from their 'classic' features. Nevertheless, these have repeatedly resurfaced in new ways that also draw on past practices, throughout the shifts in the political economy between the Mao era and beyond into the globalised market economy. Such practices have long been sustained by a discourse of gender difference 
centring on-though far from limited to-matters of marriage, reproduction, family, kinship, female virtue, and the domestic division of labour. Played out in popular culture, formal education, commercial advertisements, and much more, the critical spaces available to women to explore alternative possibilities of gender are severely constrained. So, we need to wait for further research to understand what makes the difference between those young urban women who are drawn to feminist challenges to the dominance of straight marriage and others belonging to what appears to be the same sociological category who make compromises with the heteronormative status quo.

But to end my response to your question by returning to the women of Dashalar, my analysis offers another glimpse of both the barriers to and the possibilities of change. My discussion of the only two younger women I knew-Meiling's daughter and Li Fuying's daughter-in-law-reveals stories of generational and cultural shifts in young women's foregrounding of their individual desires and aspirations, whatever the cost to their elders, and in so doing acted out the living, embodied, and emotional reality of shifts away from the examples of their mothers.

So, in thinking about how my book adds complexity and texture to debates within contemporary Chinese feminism, I would summarise the above points in two ways. First, to reiterate that, despite the huge transformations in women's lives over the past 60 years or so, little of this has been the effect of women's increasing consciousness about gender and gender relations per se. Across generational and class difference in these decades, there is little evidence that women by and large were familiar with the language of gender equality (男女平等) any more than they were with gender. The second is to say that my book clearly indicates the bodily and emotional effects of women's struggle to negotiate a way of living while shouldering huge burdens of employment and domestic care. If Wu and Dong's (2019) 'made-in-China feminism' has any real chance of taking off beyond the realms of social media to impact the lives of women who do not, or cannot, access the same kinds of debates, my analysis complicates their argument by presenting ethnographic material revealing women's attachment to heteronormative marriage, childbearing, and filial care as an exchange combining instrumental, emotional, and ethical elements.

AEP: Let me finish by asking you a question that is relevant to the issue of the Made in China Journal in which our conversation is included. Along the lines first explored by Dorothy Solinger (1999) and more recently by Sophia Woodman and Gao Zhonghua (2019), your book demonstrates that the underclasses of Beijing become urban without fully becoming citizens. Recent events in Beijing surrounding the eviction of its so-called low-end population (低端人口) seem to buttress this point. In a country which recently 
HE: A simple answer would be to reiterate that the grand claims about eradicating poverty may, in broad-brush terms, be true. However, to set the historical record straight, we have to acknowledge that this is not due to the post-reform system per se, even less so to Xi Jinping, but has built on the extraordinary transformations already introduced during the Mao years. It would also be true to say that, in a country as diverse and huge as China, the regional and spatial differences in wealth and poverty contain within them other, multiple differences of generation, gender, and ethnicity. A more politically nuanced response would be to suggest, as Doreen Massey did long ago, that the success of wealth creation and urban regeneration depends on the creation of disadvantage, in my terms of a subaltern class-a precariat, if you will-excluded from formal access to its benefits. The brutal tragedy of the 'low-end population' to me bears out the logic of this argument. Of course, it is an argument that on a different scale is also being played out in the liberal democracies of the West.

Then there is the matter of 'citizenship'. This is a concept I do not take up in the book, but I do take up the notion of recognition. My interlocutors were painfully aware that they were not treated and recognised as full persons, but were regarded as social rubbish at the bottom of the pile (最底层). Most of the middle-aged people in my book were totally urban inasmuch as they were born and grew up in Beijing and had formal Beijing household registration documents to prove it. They claimed Dashalar and its environs as their own in associating themselves with the discursive epithet of 'old Beijingers' (老北京人). They also were aware that the Chinese term for 'underclass' was inscribed with a kind of moralistic disdain just as much as it is in English. En fin, at the end of the day, the book is a project in granting recognition to a group of people who have always been denied it. It is my sadness that they will not be able to read it. 
This text is taken from Made in China Journal: Volume 6, Issue 1, 2021, edited by Ivan Franceschini and Nicholas Loubere, published 2021 by ANU Press, The Australian National University, Canberra, Australia.

doi.org/10.22459/MIC.06.01.2021.21 